\title{
Study on Influencing Mechanism of Outdoor Plant-related Particles on Indoor Environment and its Control Measures during Transitional Period in Nanjing
}

\author{
Bin Zhou ${ }^{1^{*+}}$, Lu Feng ${ }^{1+}$, Angus Shiue ${ }^{2+}$, Shih-Cheng Hu ${ }^{2+}$, Yu Wang ${ }^{1}$, Fei Li ${ }^{1}$, Ti Lin ${ }^{2}$, \\ Hui-Fang Liu ${ }^{1}$, Peng Wei ${ }^{1}$, Yang $\mathrm{Xu}^{1}$ \\ ${ }^{1}$ Department of HVAC, College of Urban Construction, Nanjing Tech University, Nanjing 210009, China \\ ${ }^{2}$ Department of Energy and Refrigerating Air-conditioning Engineering, National Taipei University of Technology, Taipei \\ 10608, Taiwan
}

\begin{abstract}
Most city trees in Nanjing are Platanus acerifolia and Populus nigra, which generate many whirling willow catkins in the air during the transitional season, yet little attention has been paid to the health risks, including itchy skin and respiratory infections, on occupants of roadside buildings. Since the air quality of these indoor spaces cannot meet WHO guidelines during the transitional season due to the influence of plant pollutants, a suitable ventilation scheme, together with air filtration measures, is urgently needed. Hence, four ventilation schemes were compared: natural ventilation, no ventilation with the door and windows closed, recirculating ventilation with a ceiling cassette fan-coil unit but no air filter, and recirculating ventilation with a ceiling cassette fan-coil unit and F7 filter. The performance of these modes was evaluated by comparing the effects of outdoor particulate matter on the indoor air quality. The results showed that the larger the particle size, the lower the I/O ratio. Furthermore, the influence of the occupants' activities on indoor particle concentrations cannot be ignored, particularly for large particles, which varied more than small particles according to indoor human activity. Therefore, we suggest operating the ceiling cassette fan-coil unit with an air filter for this application, which can reduce the indoor particle concentration to an acceptable level and decrease the potential health risk posed by plant pollutants.
\end{abstract}

Keywords: Plant pollutants; Transitional season; Infiltration air; Ventilation modes; Indoor air quality.

\section{INTRTODUCTION}

It is estimated that city people spend $90 \%$ of their time indoors (Klepeis et al., 2001), and occupants usually spend most of the time on working (Mccreddin et al., 2013). The life expectancy is estimated to be reduced by 8.6 months per person on average by air pollution such as particulate matter (PM) in EU (WHO, 2013). In 2015, an estimated death of 4.2 million people was caused by exposure to $\mathrm{PM}_{2.5}$, which accounted for $7.6 \%$ of the global death rate. Meanwhile, it resulted in disability-adjusted life-years for about 103.1 million people (Cohen et al., 2017).

The working performance was found to be closely related to indoor environment (Fanger, 2010). When there is no strong indoor pollutant source, the sub-micron particle

\footnotetext{
${ }^{+}$These authors contributed equally to this work.

* Corresponding author.

Tel.: +86-25-83239533

E-mail address: bin.zhou@njtech.edu.cn
}

concentration inside an office building is closely related to the outdoor concentration (Koponen et al., 2001). When the infiltration of $\mathrm{PM}_{2.5}$ through the building envelope was studied, it was found that the influence of ambient $\mathrm{PM}_{2.5}$ on indoor particle concentration was large for the room with small air change rate (Choi and Kang, 2017). Table 1 illustrates the recent studies on the impact of outdoor PM on the indoor environment.

Outdoor $\mathrm{PM}_{2.5}$ concentration has a seasonal variation characteristic in Nanjing (Shao et al., 2017). Although outdoor $\mathrm{PM}_{2.5}$ is mainly generated by traffic (Quang et al., 2013), a series of new problems may be caused by planting the inappropriate species of city tree (Willis and Petrokofsky, 2017). In Nanjing, a large number of Platanus acerifolia were planted as roadside trees, which would bring shade to the city in summer but also produce a lot of problems at the same time. The seed ball of Platanus acerifolia is released with numerous stiff hairs and pollen in the period between April and June each year, which are usually dispersed with the aid of wind (Ruiz and Morales, 2008). Menzel et al. (2017) have studied the pollution from pollen in April, and they suggested the countermeasures to this problem. Qiao (1986) scanned the fruit hair of Platanus 


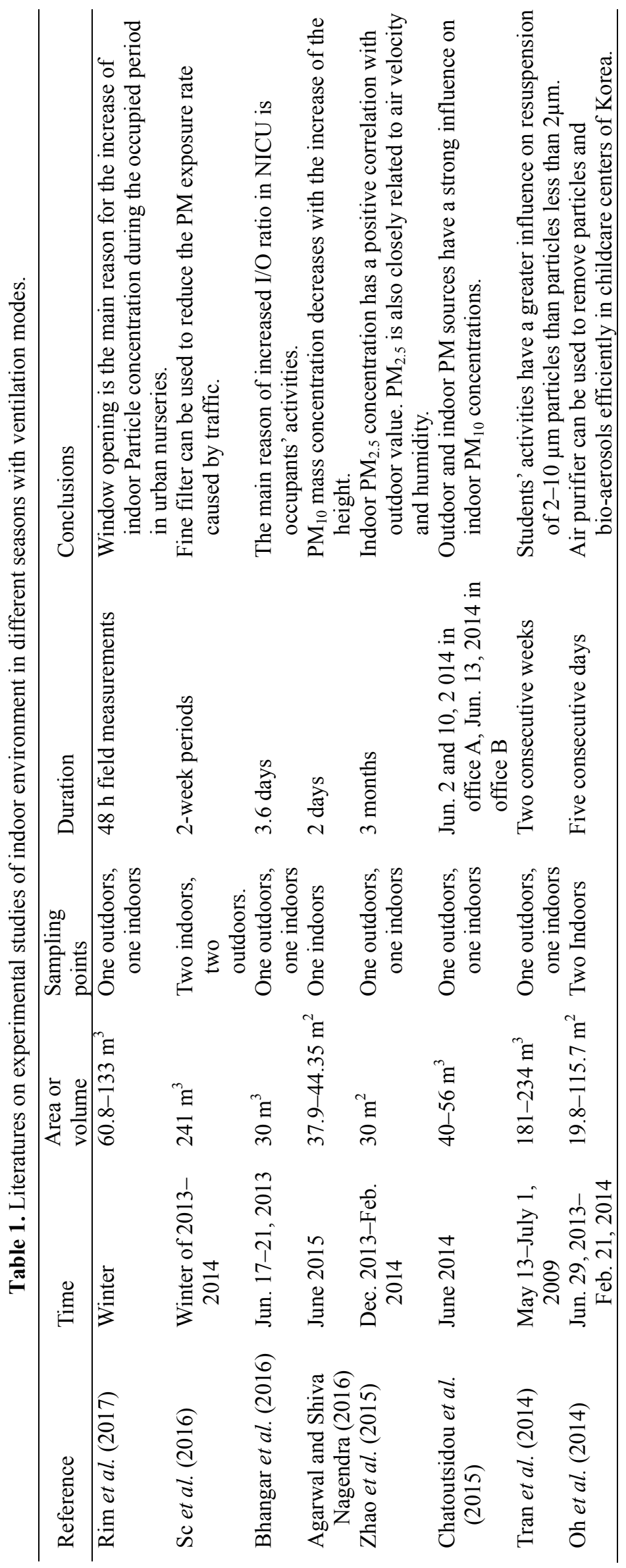


acerifolia and found that the minimum length of the fruit hair was $14-50 \mu \mathrm{m}$ and the thickness of fruit hair was about $4.3 \mu \mathrm{m}$. It is hard and brittle, so it is easily broken to produce $\mathrm{PM}_{10}$ (Qiao, 1986; Cao et al., 2008). Since the average diameter of human skin pores is $0.26-0.3 \mathrm{~mm}$, the fruit hair is likely to go through these pores when it falls onto the human skin, which will cause human skin itching and other uncomfortable effects (Cao et al., 2008). The seeds can even spread a few kilometers away under the wind condition (Nathan et al., 2002). Fruit hair will be ruptured repeatedly after landing onto the ground due to the mechanical force. It will produce inhalable $\mathrm{PM}_{2.5}$ and $\mathrm{PM}_{10}$, which may cause asthma and allergy easily (Zhang et al., 2009). Study has also shown that whirling willow catkins can cause respiratory disease, and shorten the visibility distance of pedestrians. Willow catkins are flammable substances, so they are easily caught fire. Meanwhile, whirling willow catkins will affect the accuracy of some high-precision instruments (Tang et al., 2014).

Using appropriate ventilation modes can reduce exposure to outdoor PM and improve air quality in residential buildings (Liddament, 2000). Natural ventilation is usually encouraged by existing standard in the transitional season in the hot summer and cold winter zone in China (Ministry of Housing and Urban-Rural Development of the People's Republic of China, 2012). However, when outdoor pollutant level is quite high, some occupants prefer to close the doors and windows in order to keep from the outdoor pollutants. The building envelope will act as a particulate air filter. The characteristic of infiltration air through the envelope is controlled by particle size and architectural feature (Stephens and Siegel, 2012). Gao and Zhang (2015) found that particles with size $0.05-1 \mu \mathrm{m}$ can penetrate through the door gap easily. However, so far little attention has been paid to the influence of both the outdoor PM by plant pollutant and the ventilation mode on indoor air quality in transitional season. Therefore, both theoretical and experimental study will be carried out, where special attention will be paid to the influence of PM from plant pollutant.

\section{MATERIALS AND METHODS}

\section{Site Characteristics}

Experiment was performed in a building in the Hongqiao campus of Nanjing Tech University, which is shown in Fig. 1. There is a main street which is $200 \mathrm{~m}$ away to the west of the building. Two one-way streets are $5 \mathrm{~m}$ away to the south from the building, respectively. Platanus acerifolia are planted as the roadside trees on these roads. There is a river which is $20 \mathrm{~m}$ to east of the building, where Populus nigra are planted near the river. It is shown that when the floor height is increased from $2 \mathrm{~m}$ to $79 \mathrm{~m}, \mathrm{PM}_{10}, \mathrm{PM}_{2.5}$ and $\mathrm{PM}_{1.0}$ concentrations caused by traffic can be reduced by $60 \%, 62 \%$ and $80 \%$, respectively (Wu et al., 2002). Offices on the seventh floor were chosen as the experimental site in order to reduce the influence by the traffic. The heights of each floor is $3.5 \mathrm{~m}$. The experiment office is $21 \mathrm{~m}$ above the ground.

Experiments were conducted in May 2017. The room size was $12.6 \mathrm{~m}(\mathrm{~L}) \times 5.78 \mathrm{~m}(\mathrm{~W}) \times 3.2 \mathrm{~m}(\mathrm{H})$. One ceiling cassette fan-coil unit (CCFU) with the type Gree KFR$120 \mathrm{TW} /(1251 \mathrm{~S}) \mathrm{Ba}-2$ was installed in the room. There was no dedicated outdoor air system. For the CCFU, it has a return air grille and four air outlets. The angle between the air supply blades and the ceiling is $60^{\circ}$. In the actual experiment, the maximum air volume is only used with the ventilation mode.

\section{Design of Experimental Scheme}

The experiment was conducted in two adjacent rooms with the same structure. The experimental conditions are shown in Table 2.

The experiment with occupied status was conducted during the working hours. The experiments were conducted in two periods including 9:00-11:30 a.m. and 13:30-17:00 p.m. F7 filter (equivalent to MERV 13 filter according to ASHRAE Standard 52.2) was applied in this experiment, which had average filtration efficiency larger than $90 \%$ for $0.4 \mu \mathrm{m}$ particles according to EN 779-2012. It should be

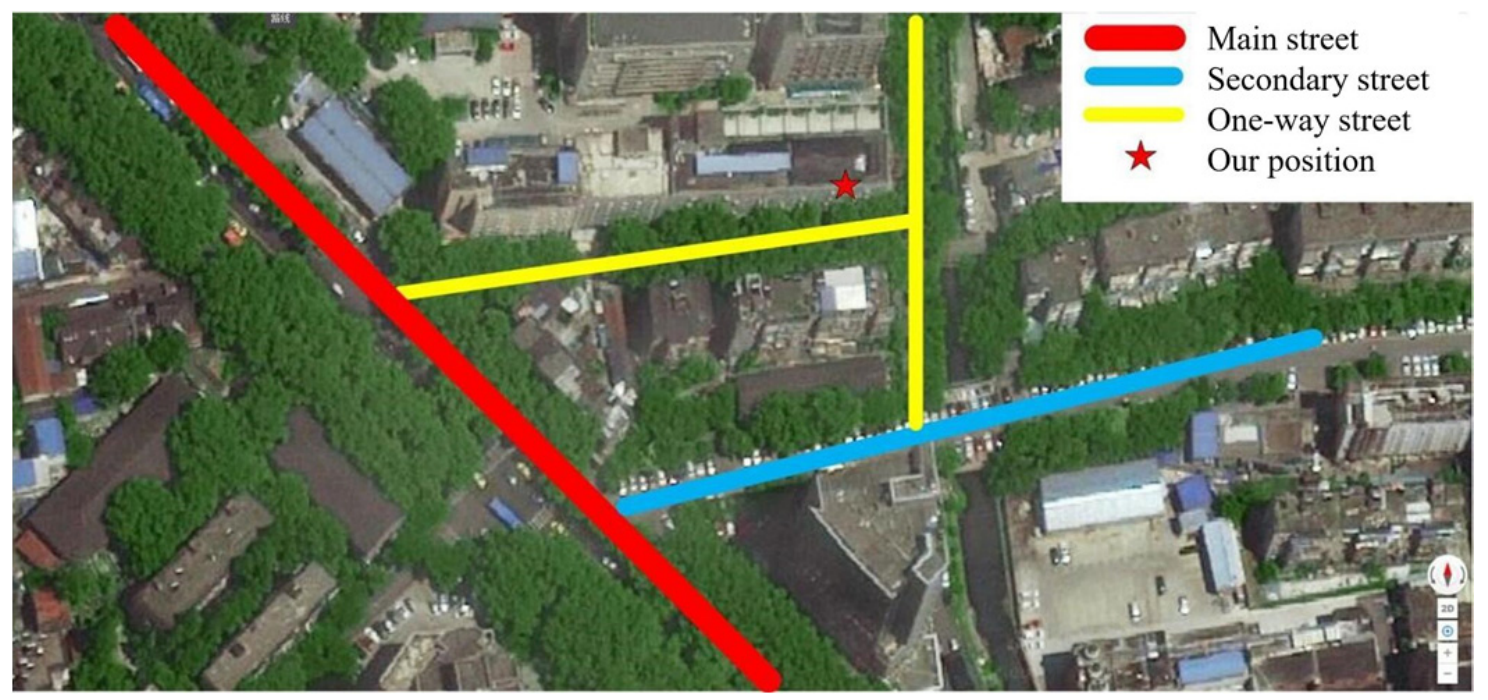

Fig. 1. Schematic diagram of the experimental building. 
Table 2. Experimental conditions.

\begin{tabular}{|c|c|c|c|c|}
\hline Experiment ID & Windows and doors & Air conditioning & Occupied status & Experiment time \\
\hline R1-A1-1 & Open & Closed & unoccupied & May 1 \\
\hline $\mathrm{R} 1-\mathrm{A} 1-2$ & Open & Closed & occupied & May 2 \\
\hline R1-A2-1 & Closed & Closed & unoccupied & May 21 \\
\hline R1-A2-2 & Closed & Closed & occupied & May 6 \\
\hline R1-A3-1 & Closed & F7 filter & unoccupied & May 17 \\
\hline R1-A3-2 & Closed & F7 filter & occupied & May 13 \\
\hline R1-A4-1 & Closed & no filter & unoccupied & May 16 \\
\hline R1-A4-2 & Closed & no filter & occupied & May 14 \\
\hline
\end{tabular}

noted that the fan has been turned on to stir the indoor air under the R1-A2-1 condition (R1 represents Room 1, and A2 represents the working condition of closing the doors and windows without ventilation). It was meant to make indoor particle concentration evenly distributed.

\section{Room Size and Measuring Points}

The locations of measurement points are shown in Fig. 2. They were $1.2 \mathrm{~m}$ above the floor, where it corresponds to the breathing height of the sitting people. According to GB50325-2010 (Ministry of Housing and Urban-Rural Development of the People's Republic of China, 2014), two sampling points should be set in a room with area between $50 \mathrm{~m}^{2}$ and $100 \mathrm{~m}^{2}$. Since the room area was $72.8 \mathrm{~m}^{2}$, two indoor sampling points and one outdoor sampling point were set.

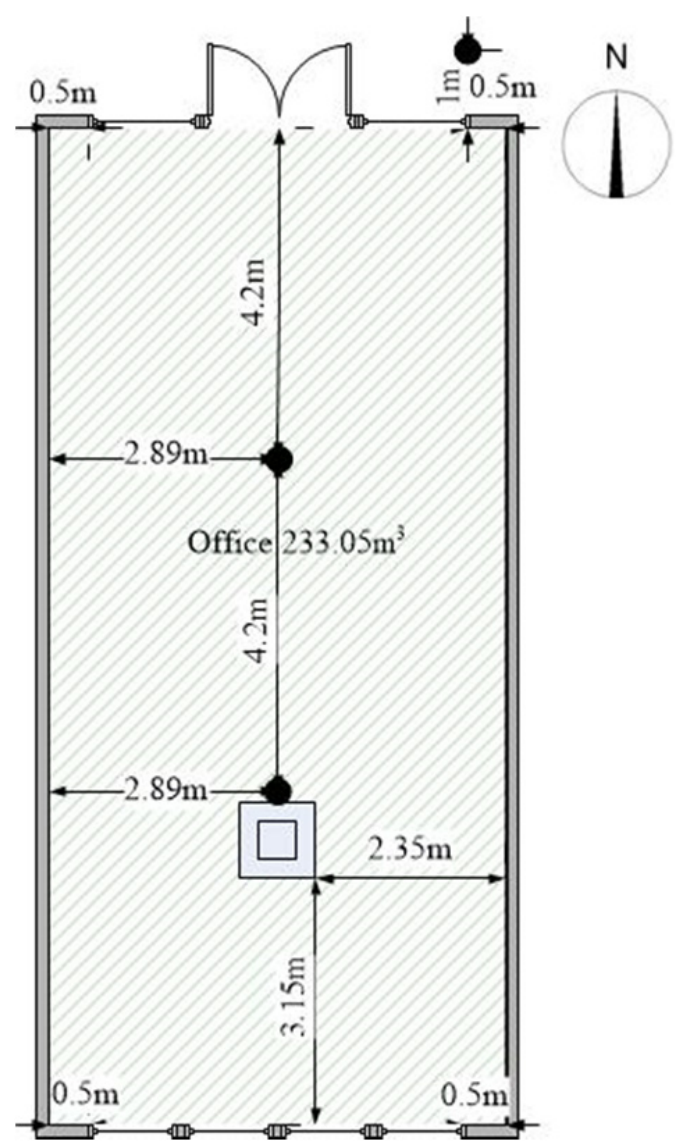

Fig. 2. Schematic diagram of the measuring points.

\section{Measurement Instruments}

Agilent 34972A was used to collect data, such as temperature, humidity, air velocity and particle mass concentration. Micro manometer and air capture hood were used for test air flow rate. The nephelometer TSI 8530 was mainly used to test the gravimetric concentration of particles. It was used to validate the accuracy of the particle mass concentration measurement instrument PMS5003. $\mathrm{PM}_{2.5}$ and $\mathrm{PM}_{10}$ concentrations were obtained by PMS5003. CLJ$3016 \mathrm{~L}$ was used for particle number concentration. The ranges for the particle size were $0.3-0.5 \mu \mathrm{m}, 0.5-1 \mu \mathrm{m}, 1-$ $3 \mu \mathrm{m}, 3-5 \mu \mathrm{m}, 5-10 \mu \mathrm{m}$ and $>10 \mu \mathrm{m}$, respectively. The measurement instruments are shown in Table 3.

\section{Air Change Rate (ACR) of Infiltration Air and PM Penetration Factor}

The ACR of infiltration air can be measured by monitoring the decay process of the indoor $\mathrm{CO}_{2}$ concentration. Firstly, both the door and the windows were closed. Secondly, $\mathrm{CO}_{2}$ was released into the room. Thirdly, the fan was turned on to stir the indoor air. When the difference of indoor $\mathrm{CO}_{2}$ concentration between the sampling points were less than $1 \%$, the indoor $\mathrm{CO}_{2}$ concentration can be determined to be uniformly distributed. Fourthly, the indoor $\mathrm{CO}_{2}$ concentration was recorded. The test conditions for infiltration air have been shown in Table 4 .

\section{THEORETICAL ANALYSIS}

\section{Lumped Parameter Method for Decay Rate of Particle Concentration}

In this study, there was neither indoor particle source nor outdoor air supply. Outdoor air infiltrated into the room through cracks and gaps on the building envelope, as well as the openings around door and windows. The indoor particle balance model can be established according to the mass balance equation (Nazaroff, 2004). The schematic diagram of the indoor particle balance model is shown in Fig. 3. The indoor particle balance equation is defined as Eq. (1):

$\frac{d C_{i}}{d t}=C_{0} \lambda_{L} P-C_{i}\left(\beta+\lambda_{L}\right)-\lambda_{F}\left(C_{\text {in }}-C_{\text {out }}\right)$

where $C_{\mathrm{i}}$ is the instantaneous concentration of indoor particle, $\mathrm{pc} \mathrm{m}^{-3} ; t$ is the decay time, $\mathrm{h} ; C_{0}$ is the outdoor particle concentration, $\mathrm{pc} \mathrm{m}^{-3} ; \lambda_{\mathrm{L}}$ is the ACR of infiltration air, $\mathrm{h}^{-1} ; P$ is the PM penetration factor; $\beta$ is the deposition 
Table 3. Measurement instruments.

\begin{tabular}{|c|c|c|c|c|c|}
\hline Parameters & Unit & Type & Accuracy & Range & Applicability \\
\hline Temperature & ${ }^{\circ} \mathrm{C}$ & DHT11 & $\pm 0.5^{\circ} \mathrm{C}$ & $-40-80^{\circ} \mathrm{C}$ & Ambient temperature \\
\hline Humidity & $\%$ RH & DHT11 & $\pm 2 \% \mathrm{RH}$ & $0-100 \%$ & Ambient humidity \\
\hline Velocity & $\mathrm{m} \mathrm{s}^{-1}$ & QS-FS & $\pm 0.3 \mathrm{~m} \mathrm{~s}^{-1}$ & $0-32.4 \mathrm{~m} \mathrm{~s}^{-1}$ & Ambient air velocity \\
\hline Velocity & $\mathrm{m} \mathrm{s}^{-1}$ & TSI $8475-300-1$ & $\pm 3 \%$ F.S. & $0-0.5 \mathrm{~m} \mathrm{~s}^{-1}$ & Air velocity through door gap \\
\hline Temperature & ${ }^{\circ} \mathrm{C}$ & OMEGA TT-T-36 & $\pm 0.5^{\circ} \mathrm{C}$ & $0-100^{\circ} \mathrm{C}$ & Temperature trough door gap \\
\hline $\begin{array}{l}\text { Particle number } \\
\text { concentration }\end{array}$ & $\mathrm{pc} / 2.83 \mathrm{~L}$ & CLJ-3016L & $\pm 3 \%$ F.S. & $10^{2}-3 \times 10^{5} \mathrm{pc} / 2.83 \mathrm{~L}$ & $\begin{array}{l}\text { Indoor \& outdoor particle } \\
\text { number concentration }\end{array}$ \\
\hline $\begin{array}{l}\text { Particle mass } \\
\text { concentration }\end{array}$ & $\mu \mathrm{g} \mathrm{m}^{-3}$ & PMS5003 & $\pm 2 \%$ & $0-500 \mu \mathrm{g} \mathrm{m}^{-3}$ & $\begin{array}{l}\text { Indoor \& outdoor particle mass } \\
\text { concentration }\end{array}$ \\
\hline $\mathrm{CO}_{2}$ concentration & PPM & TSI 7575-X & $\pm 3 \%$ & 0-5000 PРM & $\begin{array}{l}\text { Indoor \& outdoor } \mathrm{CO}_{2} \\
\text { concentration }\end{array}$ \\
\hline Air flow rate & $\mathrm{m}^{3} \mathrm{~h}^{-1}$ & FLY-1 & $\pm 5 \%$ F.S. & $100-3500 \mathrm{~m}^{3} \mathrm{~h}^{-1}$ & Flow rate through CCFU \\
\hline
\end{tabular}

Table 4. Test conditions for ACR of infiltration air and PM penetration factor.

\begin{tabular}{lllllll}
\hline Exp. ID & $\begin{array}{l}\text { Door and } \\
\text { window }\end{array}$ & Air conditioning & $\begin{array}{l}\text { Occupied } \\
\text { status }\end{array}$ & Period & $\begin{array}{l}\text { Indoor Temperature } \\
\left({ }^{\circ} \mathrm{C}\right)\end{array}$ & $\begin{array}{l}\text { Indoor Humidity } \\
(\%)\end{array}$ \\
\hline R1-B1-1 & closed & closed & unoccupied & $3 \mathrm{~h}$ & $28.8 \pm 0.4$ & $65 \pm 7$ \\
R1-B1-2 & closed & F7filter & unoccupied & $3 \mathrm{~h}$ & $29.1 \pm 0.4$ & $71 \pm 2$ \\
R1-B1-3 & closed & No filter & unoccupied & $3 \mathrm{~h}$ & $28.0 \pm 0.9$ & $70 \pm 8$ \\
\hline
\end{tabular}

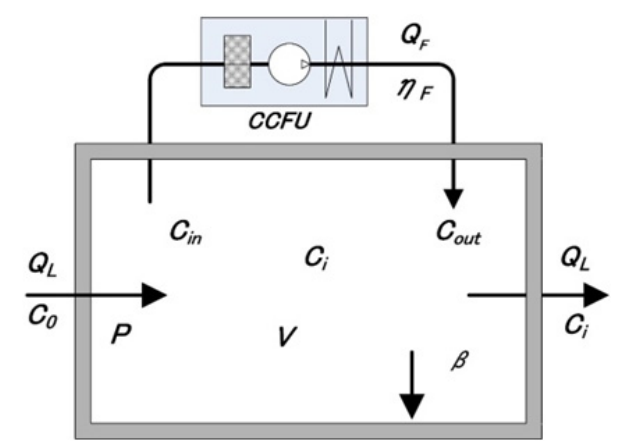

Fig. 3. Schematic diagram of the indoor particle balance model.

rate of particles, $\mathrm{h}^{-1} ; \lambda_{\mathrm{F}}$ is the ACR through the CCFU, $\mathrm{h}^{-1}$; $C_{\text {in }}$ is particle concentration at the inlet of CCFU, $\mathrm{pc} \mathrm{m}^{-3}$; $C_{\text {out }}$ is particle concentration at the outlet of CCFU, $\mathrm{pc} \mathrm{m}^{-3}$; $\mathrm{d} C_{\mathrm{i}} / \mathrm{d} t$ means the variation of indoor particle concentration; $C_{0} \lambda_{\mathrm{L}} P$ means the total number of outdoor PM penetrating indoors; $C_{\mathrm{i}}\left(\beta+\lambda_{\mathrm{L}}\right)+\lambda_{\mathrm{F}}\left(C_{\text {in }}-C_{\text {out }}\right)$ means the total number of PM loss indoors.

\section{Test on ACR of Infiltration Air}

The ACR of infiltration air into the room was tested by measuring the decay rate of $\mathrm{CO}_{2}$ concentration (Cui et al., 2015). According to the indoor $\mathrm{CO}_{2}$ mass balance equation, the variation model of indoor $\mathrm{CO}_{2}$ concentration can be established, which is defined in Eq. (2):

$$
\frac{d C_{t}}{d t}+\lambda_{L}\left[C_{t}-C_{b g}\right]=0
$$

where $C_{\mathrm{t}}$ is instantaneous indoor $\mathrm{CO}_{2}$ concentration, PPM; $t$ is decay time, $\mathrm{h} ; C_{\mathrm{bg}}$ is outdoor $\mathrm{CO}_{2}$ concentration, PPM;
$\lambda_{\mathrm{L}}$ is the ACR of the infiltration air, $\mathrm{h}^{-1} ; \mathrm{d} C_{\mathrm{t}} / \mathrm{d} t$ is the variation of indoor $\mathrm{CO}_{2}$ concentration; $\lambda_{\mathrm{L}}\left(C_{\mathrm{t}}-C_{\mathrm{bg}}\right)$ means total $\mathrm{CO}_{2}$ loss indoors.

Based on Eq. (2), Eq. (3) can be derived:

$\lambda_{L}=\frac{1}{\Delta t}\left[\ln \left(C_{\mathrm{a}}-C_{b g}\right)-\ln \left(C_{f}-C_{b g}\right)\right]$

where $\Delta t$ is the decay time, $\mathrm{h} ; C_{\mathrm{a}}$ is the initial indoor $\mathrm{CO}_{2}$ concentration, PPM; $C_{\mathrm{f}}$ is the final indoor $\mathrm{CO}_{2}$ concentration, PPM.

\section{I/O Particle Concentration Ratio}

Given the fact that both indoor and outdoor particle concentrations will change with time, the average values were obtained by multiple measurements of indoor and outdoor particle concentrations (Challoner and Gill, 2014). Then I/O ratio can be expressed with Eq. (4):

$\frac{I}{O}=\left(\frac{\sum_{1}^{n} C_{\text {indoor }}}{n}\right) \div\left(\frac{\sum_{1}^{n} C_{\text {outdoor }}}{n}\right)$

where $C_{\text {indoor }}$ is indoor particle concentration in one time step; $C_{\text {outdoor }}$ is outdoor particle concentration in one time step; $n$ is the number of time steps.

\section{Particle Deposition Rate}

The deposition rates of particles with different sizes are shown in Table 5 (Feng et al., 2017). The deposition rates of $\mathrm{PM}_{2.5}$ and $\mathrm{PM}_{10}$ are $0.4 \mathrm{~h}^{-1}$ and $1.0 \mathrm{~h}^{-1}$, respectively (Xie et al., 2013). 
Table 5. Deposition rate of particle with different sizes (Feng et al., 2017).

\begin{tabular}{ll}
\hline Particle size range $(\mu \mathrm{m})$ & Deposition rate $\beta\left(\mathrm{h}^{-1}\right)$ \\
\hline $0.3-0.5$ & $3.484 \times 10^{-3}$ \\
$0.5-0.7$ & 0.029 \\
$0.7-1.0$ & 0.0851 \\
$1.0-2.0$ & 0.336 \\
$2.0-5.0$ & 1.664 \\
\hline
\end{tabular}

\section{Measurement of PM Penetration Factor}

After all the windows and the door were closed, CCFU with F7 filter installed was turned on for 3 hours. When the indoor particle concentration reached the minimum, CCFU was turned off. The indoor particle concentration was increased until it reached stable I/O equilibrium status. The indoor particle balance equation can be expressed with Eq. (5):

$\frac{d C_{i}}{d t}=C_{0} \lambda_{L} P-C_{i}\left(\beta+\lambda_{L}\right)$

When the indoor particle concentration reached stable, i.e., $\mathrm{d} C_{\mathrm{i}} / \mathrm{d} t=0$, the formula can be simplified as Eq. (6). The detailed error analysis can be found in Appendix A as supplementary material.

$$
P=\frac{I}{O}\left(\frac{\beta}{\lambda_{L}}+1\right)
$$

\section{RESULTS AND DISCUSSION}

\section{Outdoor Particle Mass Concentration}

Long-time Monitoring

Outdoor $\mathrm{PM}_{2.5}$ and $\mathrm{PM}_{10}$ concentrations, ambient temperature, humidity and air velocity were monitored on 14 days in May of 2017. Results from Fig. 4 show that the daily mean concentrations of $\mathrm{PM}_{10}$ on about 6 monitoring days exceeded the limit set by WHO guidelines, while these of $\mathrm{PM}_{2.5}$ on only 4 monitoring days were within the limit value. Considering the health effect on occupants, it is necessary to take measures of air filtration in transitional season. In the experiment, the range of daily average temperature in 14 monitoring days was $18.7-34.0^{\circ} \mathrm{C}$. There were only 2 days when ambient temperature was above $30^{\circ} \mathrm{C}$. In this case, there was no need for refrigeration cycle. The range of average relative humidity in 14 monitoring days was about $23-75 \%$. The outdoor air velocity fluctuated between $0.6 \mathrm{~m} \mathrm{~s}^{-1}$ and $1.5 \mathrm{~m} \mathrm{~s}^{-1}$.

\section{Continuous Monitoring of Particle Concentration on One Day}

Fig. 5 shows the variation of parameters of ambient air with time on May 22. Particle concentration reached the highest value in the morning, and it fluctuated with time in 1 day. $\mathrm{PM}_{10}$ concentration at 9:00-11:30 a.m. was higher than the limit value specified by WHO guidelines. At 2:005:00 p.m. during the working time, $\mathrm{PM}_{10}$ concentration fluctuated near the limit value from WHO guideline. However, $\mathrm{PM}_{10}$ concentration after 5:00 p.m. was within the limit of WHO guideline. $\mathrm{PM}_{2.5}$ concentrations between 8:00 and 9:00 p.m. were higher than the WHO guideline value. The temperature fluctuated within the range of 24 $32^{\circ} \mathrm{C}$ and the air velocity was kept in the range of $0-2 \mathrm{~m} \mathrm{~s}^{-1}$ on this day. The fluctuation characteristic of relative humidity was similar to that of particle concentration. The highest humidity appeared in the morning, while the lower relative humidity occurred in the afternoon. Considering the variation feature of the particle mass concentration in one day, it is recommended that the indoor air filtration measures should be taken in the morning in order to protect occupants' health.

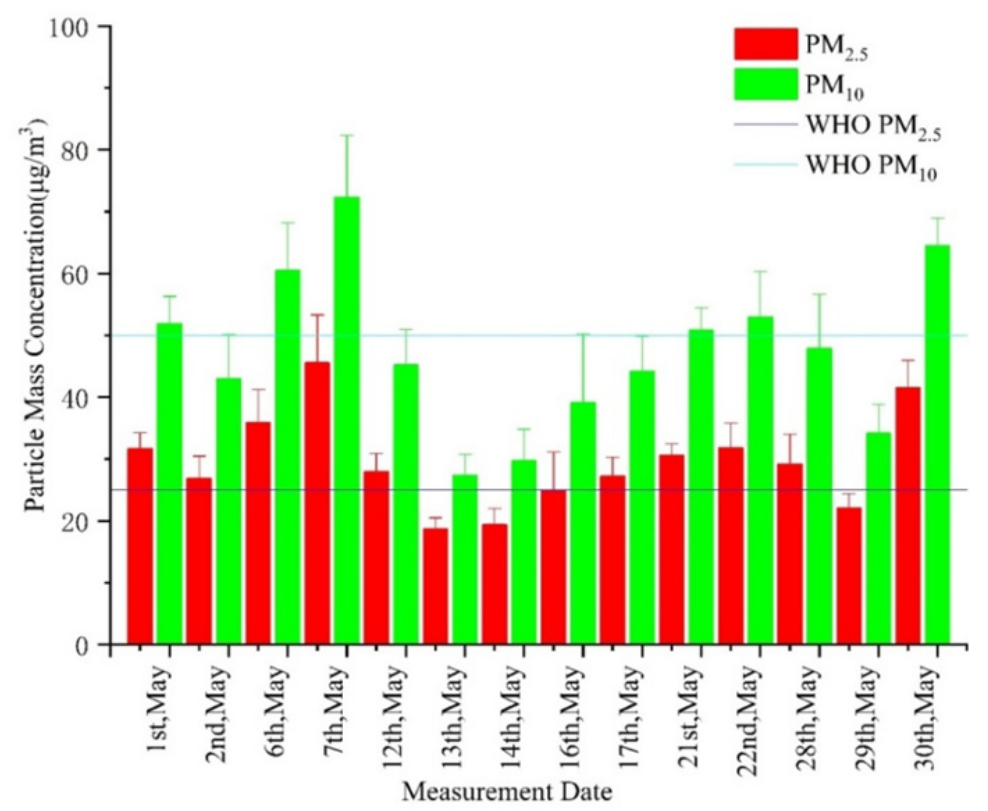

Fig. 4. Sampled outdoor particle concentrations in May of 2017. 


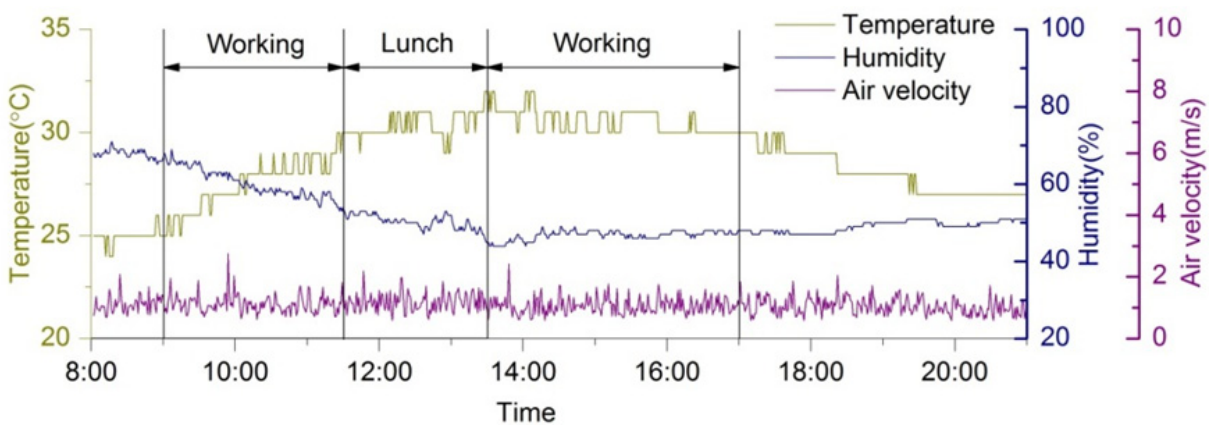

(a)

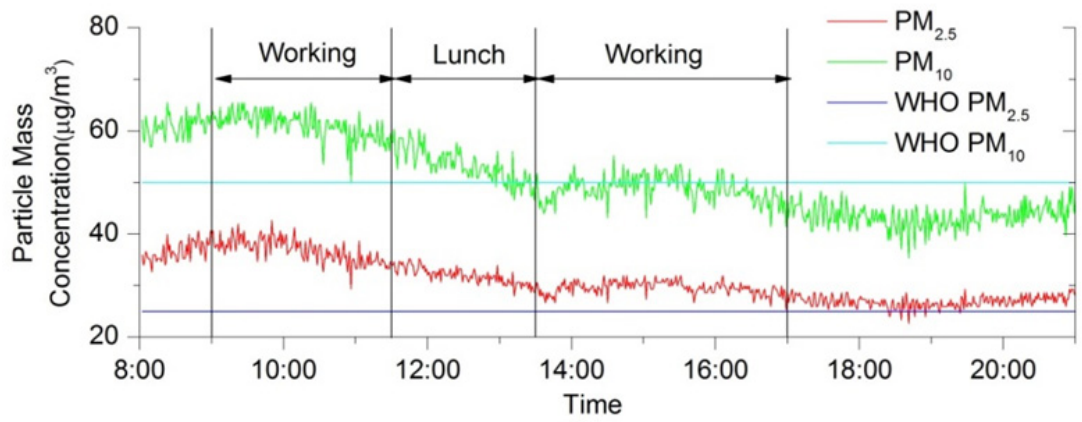

(b)

Fig. 5. Variation of outdoor particle concentration with time on May 22.

\section{Test of ACR and Penetration Factor}

ACR of Recirculating Air

Air capture hood was used to measure the airflow rate of CCFU. Fig. 6(a) shows ACR of recirculating air through CCFU. For the situation of R1-B1-1, CCFU was closed so that ACR of recirculating air was zero. Compared with the situation of R1-B1-3 (CCFU without air filter), the ACR of recirculating air through the $\mathrm{CCFU}$ for the situation of $\mathrm{R} 1-$ B1-2 (with F7 filter installed) was decreased by about $54.00 \%$.

\section{ACR of Infiltration Air and Penetration Factor}

ACR of infiltration air is shown in Fig. 6(b). It is suggested in the relevant standard that the ACR in office should be $1.5 \mathrm{~h}^{-1}$ at least (Lu, 2008). The ACR of infiltration air was enough to meet the demand for outdoor air. The penetration factor can be calculated from Eq. (6). Chao et al. (2003), Long et al. (2001), Thatcher et al. (2003), Vette et al. (2001) and Zhu et al. (2005) have also performed tests on the penetration factor. Chen et al. (2011) have summarized the penetration factor in the literature. The values of penetration factors for $0.3-10 \mu \mathrm{m}$ particles were chosen to compare with our results. Comparative results in Fig. 7 show that particle penetration factor of our study was similar to those measured in other literatures. The measured results were as follows: The penetration factors for particles with diameter $0.3-0.5 \mu \mathrm{m}, 0.5-1.0 \mu \mathrm{m}, 1.0$ $3.0 \mu \mathrm{m}, 3.0-5.0 \mu \mathrm{m}$ and $5.0-10.0 \mu \mathrm{m}$ were $0.78,0.74$, $0.51,0.38$ and 0.28 , respectively.

From Eq. (6), it is known that the particle penetration factor is influenced by the pressure difference between indoors and outdoors, the size of the door gap, the surface roughness of the door gap, and the temperature difference.
The larger the particle size is, the smaller the particle penetration factor is. For larger particles, the particle penetration factor is relatively smaller because of the influence of gravitational deposition.

\section{Indoor and Outdoor Plant-related Particle Sedimentation}

Cao et al. (2008) applied the electron microscope to amplify the fiber-like pollutants, the details of which are shown in Fig. 8. Moreover, except for the influence of Platanus acerifolia in the transitional season, there is also cross-contamination of whirling willow catkins, which is shown in Fig. 9.

The atmospheric conditions with and without plant pollutants are compared to investigate the influence of the plant pollutant from ambient air on the indoor air quality. The experimental procedures are as follows: Under different experimental conditions, two petri dishes were placed in the indoor and outdoor areas to settle the particles in the air, and the settling time was 3 hours. The plates were magnified by 50 times under a stereo microscope. Ten pictures were randomly taken on each petri dish to count the number of contaminants in the petri dish and the contamination of the plants. The number of objects is taken as the concentration of plant contaminants in the petri dish. Plant pollutants are counted only by number, regardless of size.

Part of the sedimentation photos is shown in Fig. 10. The deposition morphology of both the seed of Populus nigra and fibrous contaminant caused by fruit hair can be clearly seen. The fibrous sediments are the fruit hairs of Platanus acerifolia, and the spider-like sediments are the flocks of Populus nigra.

Fig. 11 shows the average count of indoor and outdoor particles in the area of $4.92 \mathrm{~mm}^{2}$. It can be seen from the 


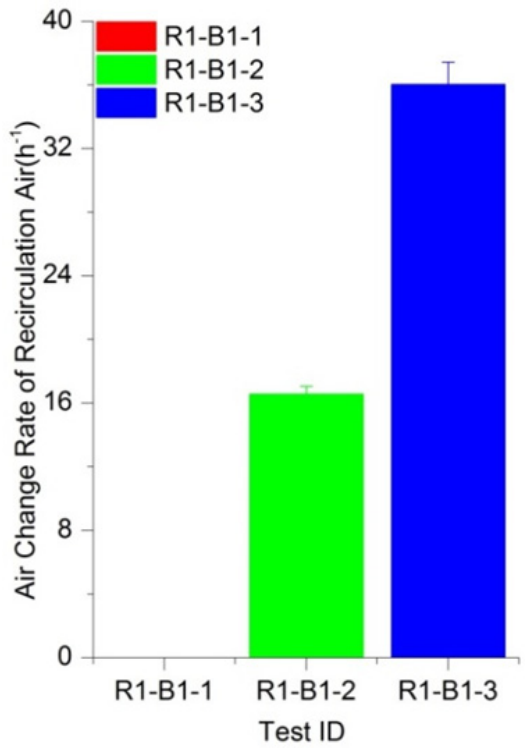

(a)

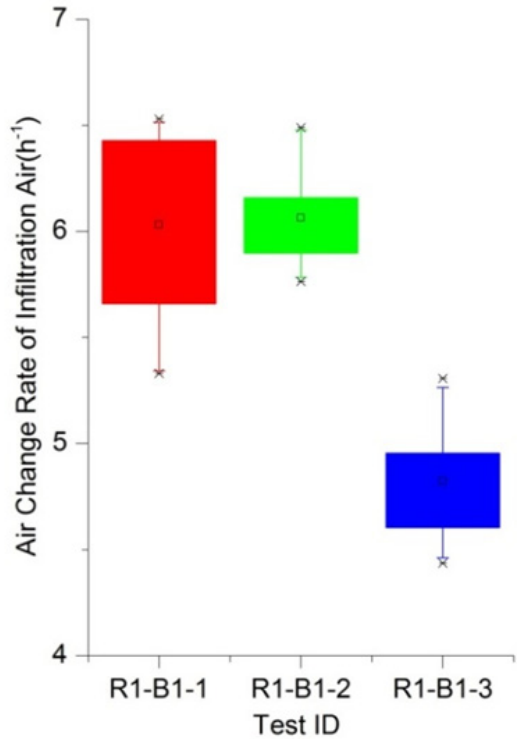

(b)

Fig. 6. Characteristics of ACRs of recirculating air and infiltration air indoors. (a) ACR of recirculating air; (b) ACR of infiltration air.

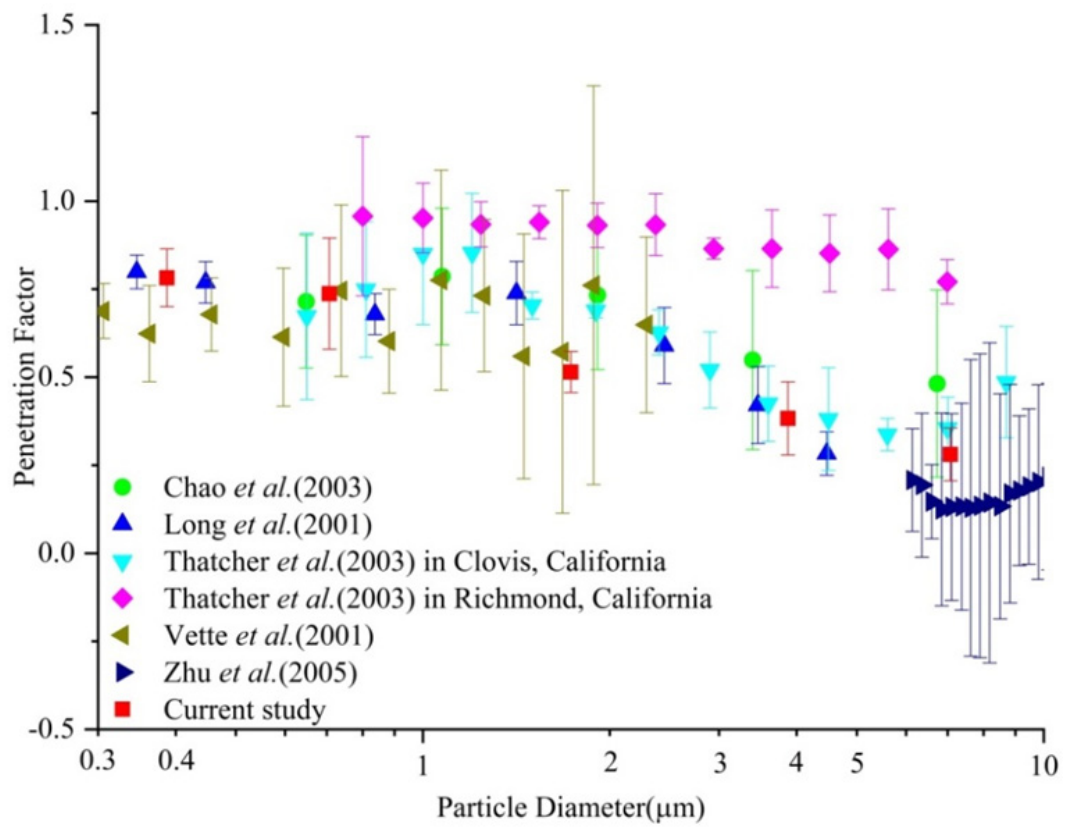

Fig. 7. Comparison on penetration factors between this study and others.

figure that the number of outdoor particles ranges from 20 to 40 particles in the area of $4.92 \mathrm{~mm}^{2}$. Particularly, the number of particles from plant pollutants accounts for about $2-10 \%$ of total number. From Fig. 12, it can be seen that the number of particles under natural ventilation conditions is the highest. Compared with the internal circulation conditions with CCFU alone, the concentration of indoor particles decreases by approximately $18.21 \%$ under the conditions of CCFU with air filters. Moreover, with the above-mentioned experimental procedures, the proportion of plant particles indoors could be decreased by approximately $69.56 \%$. It can be seen that installing air filters in CCFU can effectively reduce the concentration of indoor plantrelated particles.

\section{Indoor Particle Concentration}

Particle Mass Concentration

Descriptive statistics of indoor particle mass concentrations under different ventilation strategies are shown in Table 6. It was found that the mean value and the standard deviation were not enough to describe the indoor particle concentration. This was because the indoor particle concentration varied with outdoor concentration. Therefore, coefficient of variation $(\mathrm{CV})$ was used to describe the 


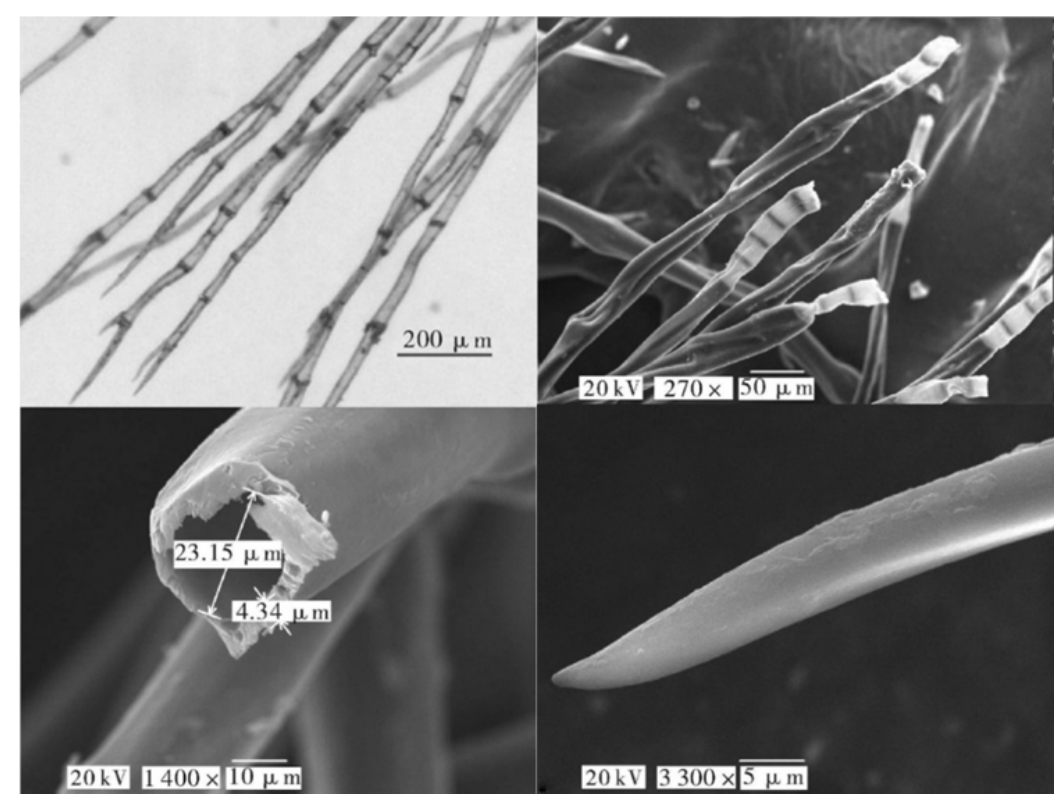

Fig. 8. The morphology of fruit hair of Platanus acerifolia and its enlarged component (Cao et al., 2008).

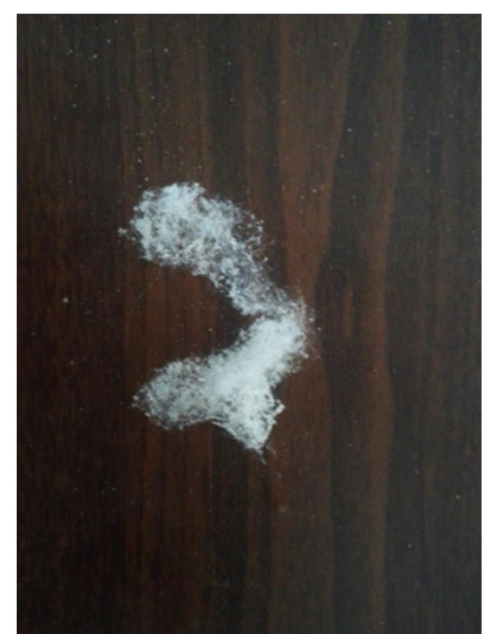

Fig. 9. Schematics of willow catkins from Populus nigra on working table.

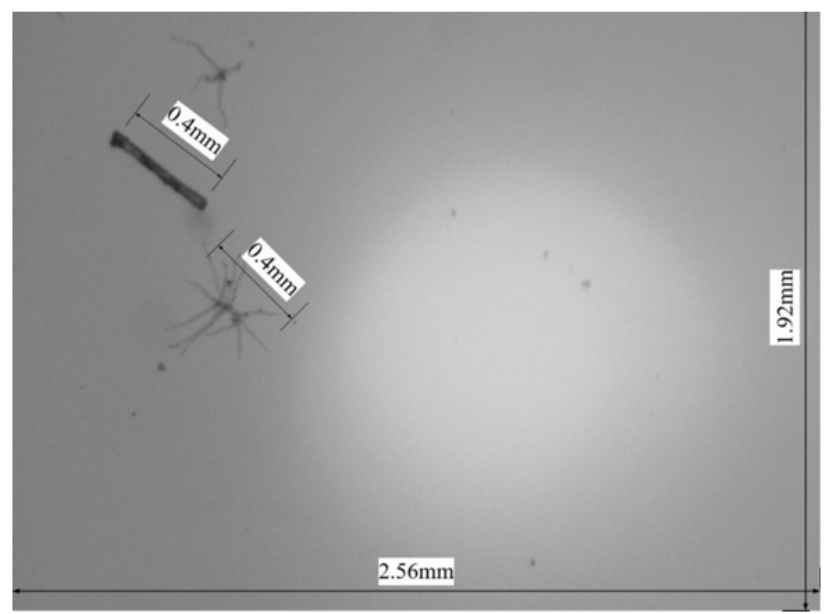

Fig. 10. The picture of indoor deposited air pollutants taken by stereo microscope. fluctuation characteristic of particle concentration, which means the ratio of the standard deviation to the mean value and acts as a measure of relative variability for the particle concentration. It was found that $\mathrm{CV}$ in occupied condition was larger than that of unoccupied condition. This was because there was occupants' activity indoors which resuspended the indoor deposited particles. It is clear that the operation of CCFU with F7 filter installed would reduce indoor $\mathrm{PM}_{2.5}$ and $\mathrm{PM}_{10}$ concentrations. When $\mathrm{CCFU}$ with F7 filter was applied, both the indoor $\mathrm{PM}_{2.5}$ and $\mathrm{PM}_{10}$ concentrations could meet the requirement of WHO guidelines. Compared with the condition of operating CCFU without air filter, the $\mathrm{I} / \mathrm{O}$ value is statistically significantly different under the condition of operating CCFU with F7 filter by application of $t$-test. This means that installation of F7 filter in CCFU could significantly improve indoor air quality.

\section{Particle Number Concentration}

Descriptive statistics of indoor particle number concentrations under different ventilation strategies are shown in Table 7. It can be seen that the CV in occupied condition was larger than that in unoccupied condition. The larger the particle size was, the higher the $\mathrm{CV}$ value was. This was because occupants' activities had larger influence on large particle than that for small particle. The $\mathrm{CV}$ of outdoor particle concentration remained stable at a low level in all experiments. For indoor particles, it is shown that $\mathrm{CV}$ of indoor small particle concentration was similar to that of outdoor small particle concentration. However, CVs of large particles with diameter 3.0-5.0 $\mu \mathrm{m}$ and 5.0-10.0 $\mu \mathrm{m}$ between indoors and outdoors had opposite trend. This was due to the fact that small particle with diameter $0.3-0.5 \mu \mathrm{m}$ and $0.5-1.0 \mu \mathrm{m}$ had larger penetration factor, so indoor particle concentrations with diameter $0.3-$ $0.5 \mu \mathrm{m}$ and $0.5-1.0 \mu \mathrm{m}$ were easily dominated by outdoor 


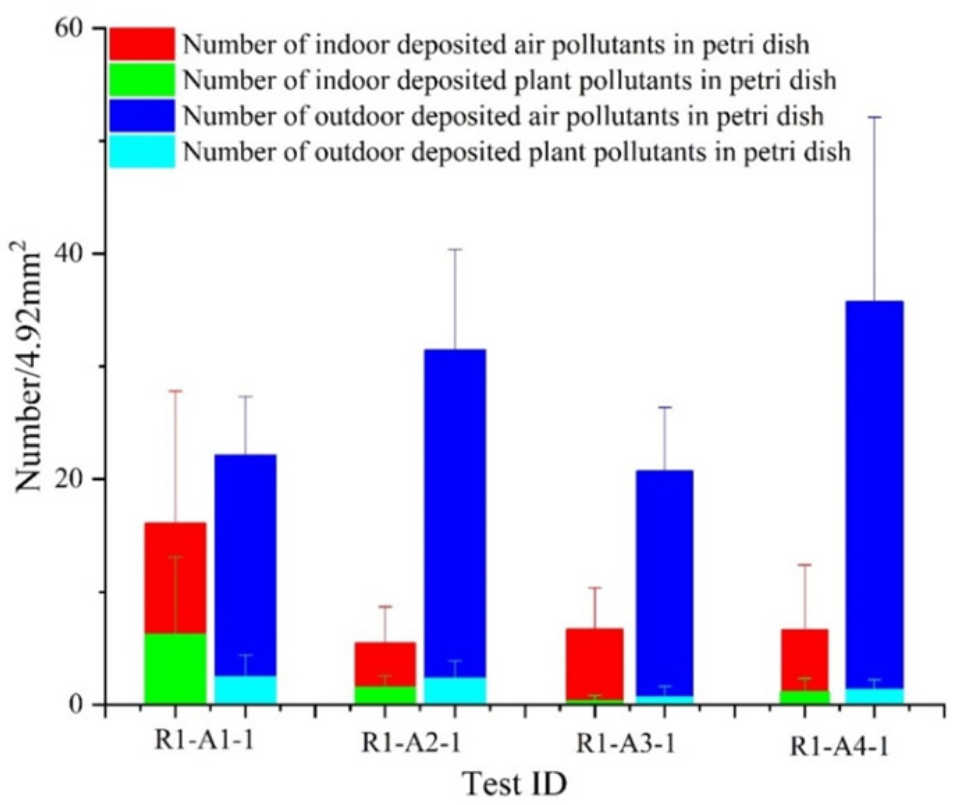

Fig. 11. The counting concentration of indoor and outdoor botanic particles.

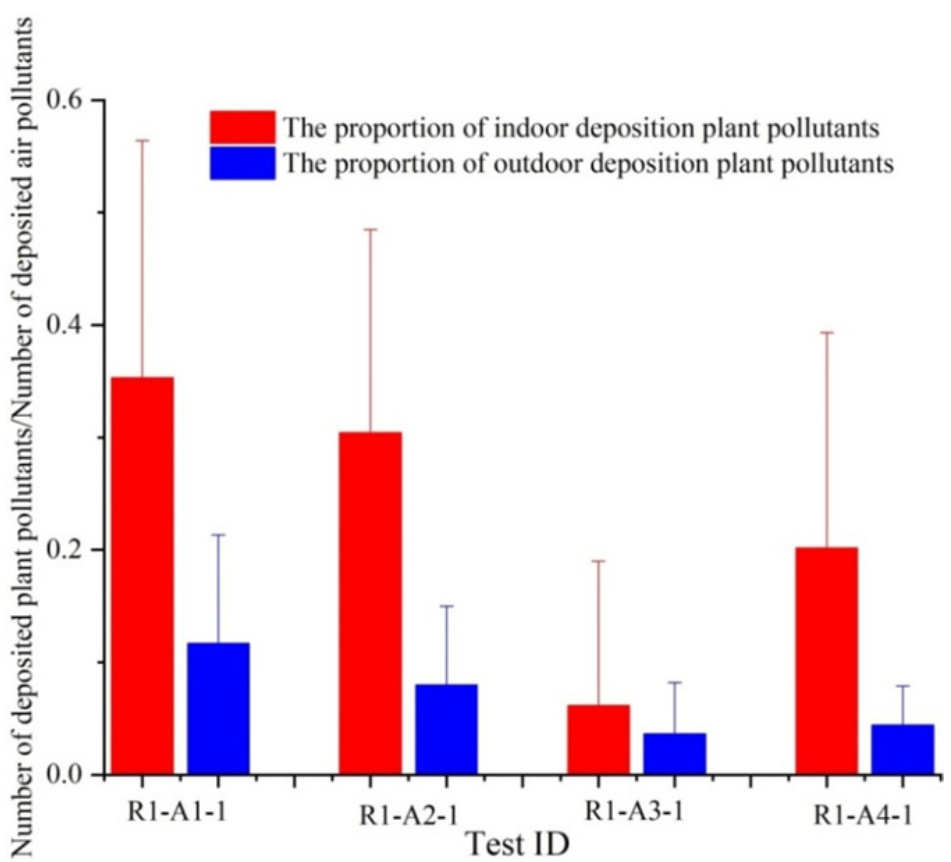

Fig. 12. The ratio of the plant-related particles to the total particles.

value. However, large particle with diameter 3.0-5.0 $\mu \mathrm{m}$ and 5.0-10.0 $\mu \mathrm{m}$ had lower penetration factor, so occupants' activities would exert more important influence on concentration of large particles.

\section{I/O Ratio}

\section{Effect of Different Conditions on I/O Ratio}

It is shown from Fig. 13 that under R1-A3 and R1-A4 conditions, $\mathrm{PM}_{2.5} \mathrm{I} / \mathrm{O}$ ratio of occupied condition was larger than that of unoccupied condition by $10.34 \%$ and $33.76 \%$, respectively. While for $\mathrm{PM}_{10}$, the corresponding $\mathrm{I} / \mathrm{O}$ ratios were increased by $19.68 \%$ and $40.63 \%$, respectively.
However, for R1-A2 situation, $\mathrm{PM}_{2.5}$ and $\mathrm{PM}_{10}$ concentrations in occupied condition were smaller than that in unoccupied condition by $0.21 \%$ and $2.87 \%$, respectively. Challoner and Gill (2014) obtained the similar conclusion with this experiment in Site $\mathrm{N}_{t} 5$, where the I/O ratio under unoccupied condition was larger than that under occupied condition. In this paper, I/O ratio under unoccupied condition was larger for R1-A2 situation, which was owing to the operation of indoor fan before the experiment. For the R1-A1 situation, $\mathrm{PM}_{2.5}$ and $\mathrm{PM}_{10} \mathrm{I} / \mathrm{O}$ ratios under the occupied condition were less than that under unoccupied condition by $5.68 \%$ and $12.22 \%$, respectively. While for R1-A2 situation 
Table 6. Descriptive statistics of indoor particle mass concentrations under different ventilation strategies.

\begin{tabular}{|c|c|c|c|c|c|c|c|c|}
\hline & & Mean & St. Dev. & $\mathrm{CV}$ & Geo. Mean & Median & Percentile 5.0 & Percentile 95.0 \\
\hline \multicolumn{9}{|l|}{ Indoor } \\
\hline \multirow[t]{2}{*}{ R1-A1-1 } & $\mathrm{PM}_{2.5}$ & 30.57 & 0.98 & 0.03 & 30.55 & 30.24 & 28.98 & 32.13 \\
\hline & $\mathrm{PM}_{10}$ & 49.95 & 2.08 & 0.04 & 49.91 & 49.80 & 46.64 & 52.96 \\
\hline \multirow[t]{2}{*}{ R1-A1-2 } & $\mathrm{PM}_{2.5}$ & 26.85 & 6.71 & 0.25 & 26.22 & 25.20 & 21.42 & 39.69 \\
\hline & $\mathrm{PM}_{10}$ & 41.27 & 8.90 & 0.22 & 40.47 & 38.73 & 32.41 & 55.33 \\
\hline \multirow[t]{2}{*}{ R1-A2-1 } & $\mathrm{PM}_{2.5}$ & 31.43 & 0.91 & 0.03 & 31.42 & 31.21 & 29.94 & 33.13 \\
\hline & $\mathrm{PM}_{10}$ & 52.21 & 2.11 & 0.04 & 52.17 & 52.65 & 48.60 & 55.89 \\
\hline \multirow[t]{2}{*}{ R1-A2-2 } & $\mathrm{PM}_{2.5}$ & 39.49 & 5.32 & 0.13 & 39.18 & 38.43 & 34.02 & 47.88 \\
\hline & $\mathrm{PM}_{10}$ & 64.03 & 6.06 & 0.09 & 63.79 & 63.07 & 58.49 & 72.72 \\
\hline \multirow[t]{2}{*}{ R1-A3-1 } & $\mathrm{PM}_{2.5}$ & 17.63 & 1.56 & 0.09 & 17.56 & 17.64 & 15.12 & 20.16 \\
\hline & $\mathrm{PM}_{10}$ & 24.95 & 2.92 & 0.12 & 24.79 & 24.50 & 21.34 & 30.04 \\
\hline \multirow[t]{2}{*}{ R1-A3-2 } & $\mathrm{PM}_{2.5}$ & 13.05 & 1.80 & 0.14 & 12.93 & 12.60 & 10.71 & 17.01 \\
\hline & $\mathrm{PM}_{10}$ & 18.36 & 2.74 & 0.15 & 18.17 & 17.39 & 15.02 & 23.71 \\
\hline \multirow[t]{2}{*}{ R1-A4-1 } & $\mathrm{PM}_{2.5}$ & 15.99 & 1.26 & 0.08 & 15.94 & 15.93 & 14.01 & 18.47 \\
\hline & $\mathrm{PM}_{10}$ & 22.39 & 1.98 & 0.09 & 22.31 & 21.87 & 19.44 & 25.92 \\
\hline \multirow[t]{2}{*}{ R1-A4-2 } & $\mathrm{PM}_{2.5}$ & 20.05 & 2.07 & 0.10 & 19.94 & 20.16 & 17.01 & 23.56 \\
\hline & $\mathrm{PM}_{10}$ & 30.33 & 4.52 & 0.15 & 30.00 & 30.04 & 23.71 & 38.41 \\
\hline \multicolumn{9}{|l|}{ Outdoor } \\
\hline \multirow[t]{2}{*}{ R1-A1-1 } & $\mathrm{PM}_{2.5}$ & 32.63 & 3.09 & 0.09 & 32.50 & 31.31 & 29.31 & 38.64 \\
\hline & $\mathrm{PM}_{10}$ & 53.50 & 4.78 & 0.09 & 53.30 & 52.61 & 47.44 & 62.10 \\
\hline \multirow[t]{2}{*}{ R1-A1-2 } & $\mathrm{PM}_{2.5}$ & 30.17 & 1.15 & 0.04 & 30.14 & 29.98 & 27.98 & 31.98 \\
\hline & $\mathrm{PM}_{10}$ & 49.51 & 2.36 & 0.05 & 49.45 & 50.03 & 44.85 & 52.61 \\
\hline \multirow[t]{2}{*}{ R1-A2-1 } & $\mathrm{PM}_{2.5}$ & 30.34 & 1.70 & 0.06 & 30.29 & 30.49 & 27.84 & 33.14 \\
\hline & $\mathrm{PM}_{10}$ & 50.90 & 3.28 & 0.06 & 50.79 & 50.88 & 46.57 & 56.92 \\
\hline \multirow[t]{2}{*}{ R1-A2-2 } & $\mathrm{PM}_{2.5}$ & 38.24 & 2.23 & 0.06 & 38.18 & 38.30 & 34.64 & 41.97 \\
\hline & $\mathrm{PM}_{10}$ & 64.08 & 2.46 & 0.04 & 64.04 & 63.83 & 60.38 & 68.14 \\
\hline \multirow[t]{2}{*}{ R1-A3-1 } & $\mathrm{PM}_{2.5}$ & 26.56 & 1.22 & 0.05 & 26.53 & 26.65 & 24.65 & 28.64 \\
\hline & $\mathrm{PM}_{10}$ & 42.61 & 2.08 & 0.05 & 42.55 & 42.26 & 38.81 & 45.71 \\
\hline \multirow[t]{2}{*}{ R1-A3-2 } & $\mathrm{PM}_{2.5}$ & 17.65 & 1.11 & 0.06 & 17.62 & 17.95 & 15.99 & 19.32 \\
\hline & $\mathrm{PM}_{10}$ & 25.26 & 2.06 & 0.08 & 25.18 & 25.01 & 22.43 & 28.46 \\
\hline \multirow[t]{2}{*}{ R1-A4-1 } & $\mathrm{PM}_{2.5}$ & 26.18 & 5.75 & 0.22 & 25.67 & 24.52 & 19.88 & 35.13 \\
\hline & $\mathrm{PM}_{10}$ & 41.66 & 9.28 & 0.22 & 40.73 & 39.67 & 29.75 & 55.19 \\
\hline \multirow[t]{2}{*}{ R1-A4-2 } & $\mathrm{PM}_{2.5}$ & 20.85 & 2.10 & 0.10 & 20.75 & 20.65 & 17.32 & 24.65 \\
\hline & $\mathrm{PM}_{10}$ & 31.95 & 4.54 & 0.14 & 31.63 & 31.05 & 25.88 & 39.68 \\
\hline
\end{tabular}

where the window and the door were closed and CCFU was turned off, the $\mathrm{I} / \mathrm{O}$ ratios were larger than that under R1-A1 condition.

Fig. 14 illustrates the variation of indoor and outdoor particle concentrations under occupied and unoccupied conditions. The fluctuation of particle concentration under occupied condition was relatively large. Average indoor $\mathrm{PM}_{2.5}$ concentration was lower than outdoor value. Indoor particle concentration under unoccupied condition remained more stable. In 1 hour, the indoor particle concentration became almost the same as the outdoor value. Tran et al. (2014) found that the particle mass concentration of indoor $\mathrm{PM}_{10}$ varied a lot due to occupants' activities, whereas the outdoor $\mathrm{PM}_{10}$ mass concentration was less variable. Our finding agreed well with their conclusions.

Comparison with Other Studies

Comparison of the $\mathrm{I} / \mathrm{O}$ ratios with other references is shown in Table 8 . The $\mathrm{I} / \mathrm{O}$ ratio with natural ventilation was between I/O ratios of smoking and non-smoking rooms in research from Horemans and Van Grieken (2010). With no ventilation condition, the measured $\mathrm{I} / \mathrm{O}$ ratio in this study was larger than those obtained from Zhao et al. (2015) and Challoner and Gill (2014). Part of the reason may be related to the operation of fan before the experiment. With mechanical ventilation, $\mathrm{I} / \mathrm{O}$ ratio measured in this study was similar to the value measured by Kuo and Shen (2010) during the period of dust storm. For mechanical ventilation with F7 filter installed in CCFU, the measured I/O ratio value was larger than the value measured by Chatoutsidou et al. (2015), but it was similar to the value measured by Challoner and Gill (2014).

\section{Effect of Particle Size on I/O Ratio}

I/O ratios for particles with different sizes are presented in Fig. 15. The larger the particle size was, the lower the $\mathrm{I} / \mathrm{O}$ ratio was. This is applicable to all the scenarios except for the R1-A1-1 condition which is more related to the outdoor concentration. This is due to the fact that small particle has a larger penetration factor which means that indoor small particle is greatly affected by ambient environment. Compared with particles larger than $0.5 \mu \mathrm{m}$ in the same condition, the $\mathrm{I} / \mathrm{O}$ ratio for particles in the size 


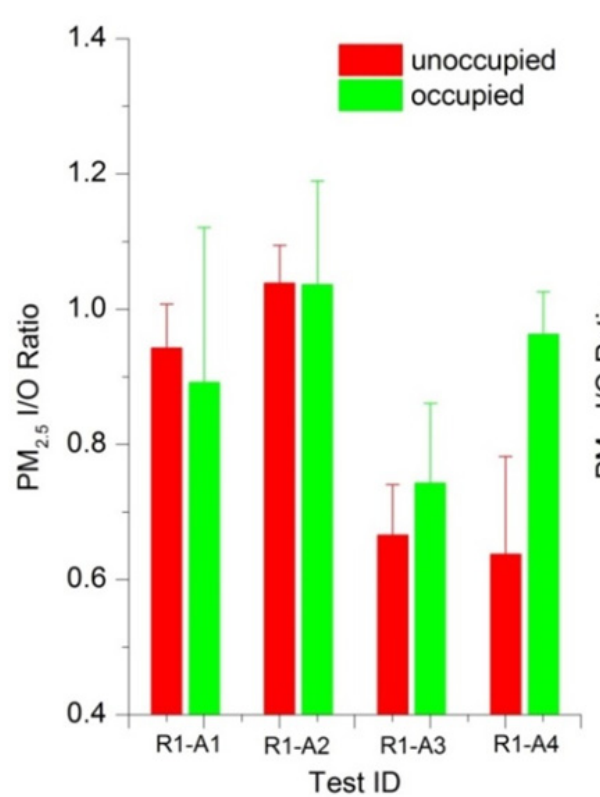

(a)

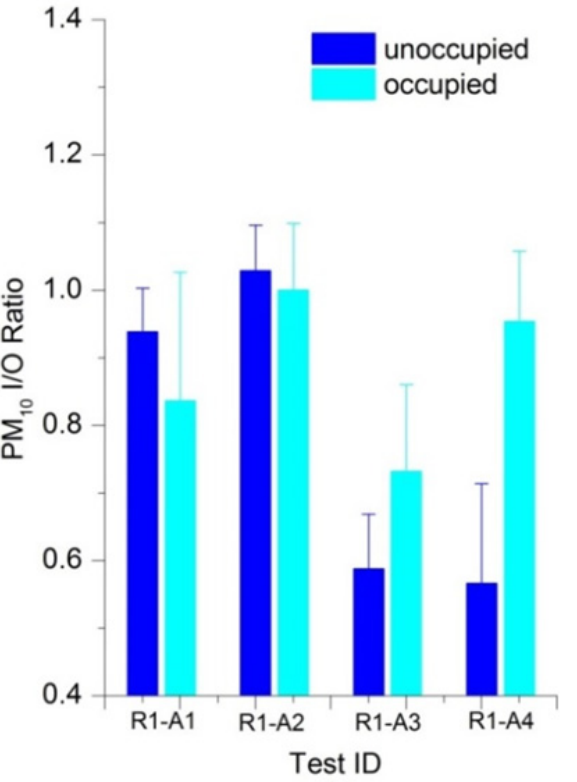

(b)

Fig. 13. I/O ratios of $\mathrm{PM}_{2.5}$ and $\mathrm{PM}_{10}$ under both occupied and unoccupied conditions.
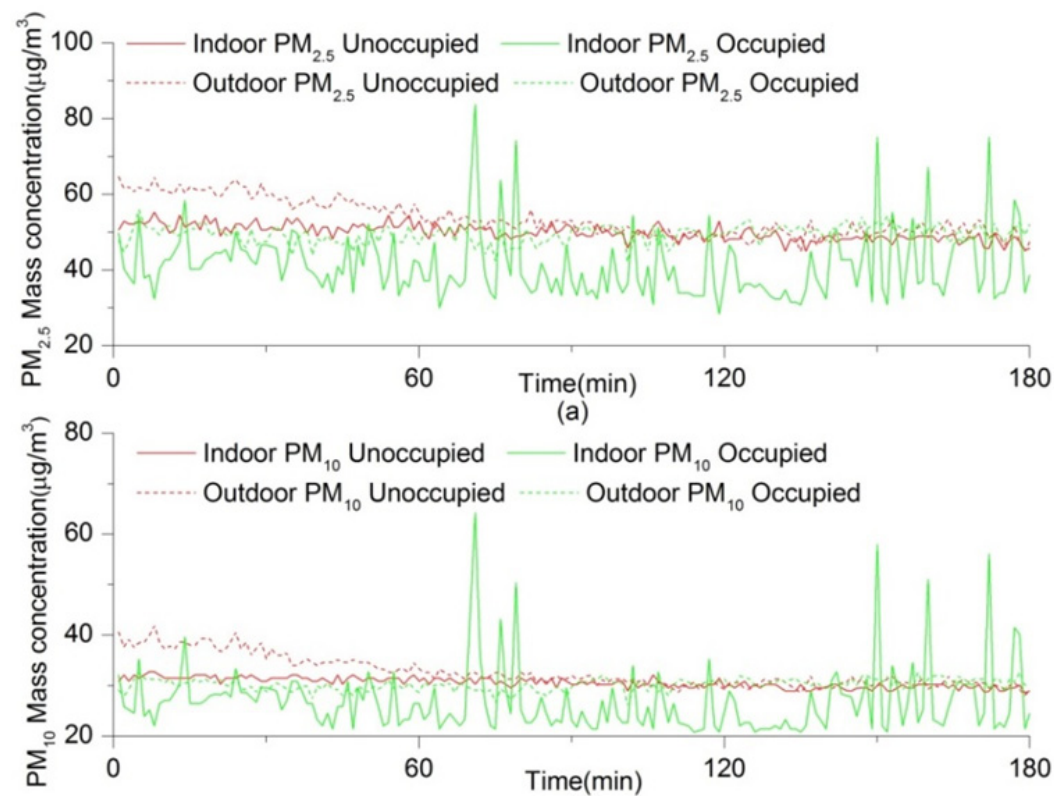

(b)

Fig. 14. Indoor and outdoor particle concentrations in R1-A1 situation.

range of $0.3-0.5 \mu \mathrm{m}$ was larger. The impact of outdoor particle concentration on indoor particle concentrations with size $3.0-5.0 \mu \mathrm{m}$ and $5.0-10.0 \mu \mathrm{m}$ was smaller. Gao and Zhang (2015) found that $0.05-1 \mu \mathrm{m}$ particles were more likely to penetrate through the slit. This agrees with the finding in the current study, where particles with size less than $1 \mu \mathrm{m}$ were greatly influenced by outdoor particles. For the $3.0-5.0 \mu \mathrm{m}$ and $5.0-10.0 \mu \mathrm{m}$ particles, they were affected by the indoor occupants' activities. When I/O ratios in R1-A1-1 and R1-A2-1 conditions were compared, it was found that $\mathrm{I} / \mathrm{O}$ ratios for particle with diameter $0.3-$ $0.5 \mu \mathrm{m}$ and $0.5-1.0 \mu \mathrm{m}$ between $\mathrm{R} 1-\mathrm{A} 2-1$ situation (infiltration) and R1-A1-1 condition (natural ventilation) are close to each other. This is because the penetration rate through the door gap for particle with diameter $0.3-0.5 \mu \mathrm{m}$ and $0.5-1.0 \mu \mathrm{m}$ is very large. However, for particle with diameter $1.0-3.0 \mu \mathrm{m}, 3.0-5.0 \mu \mathrm{m}$ and $5.0-10.0 \mu \mathrm{m}$, the $\mathrm{I} / \mathrm{O}$ ratio under $\mathrm{R} 1-\mathrm{A} 1-1$ situation (natural ventilation) is slightly larger than that under R1-A2-1 condition (infiltration when windows and doors are closed). This is because the indoor particle concentration in R1-A1-1 situation is more influenced by outdoor concentration. Compared with R1A4-1 condition, the $\mathrm{I} / \mathrm{O}$ ratio of $\mathrm{R} 1-\mathrm{A} 3-1$ condition for particles with diameter $0.3-1.0 \mu \mathrm{m}$ was smaller. This is 


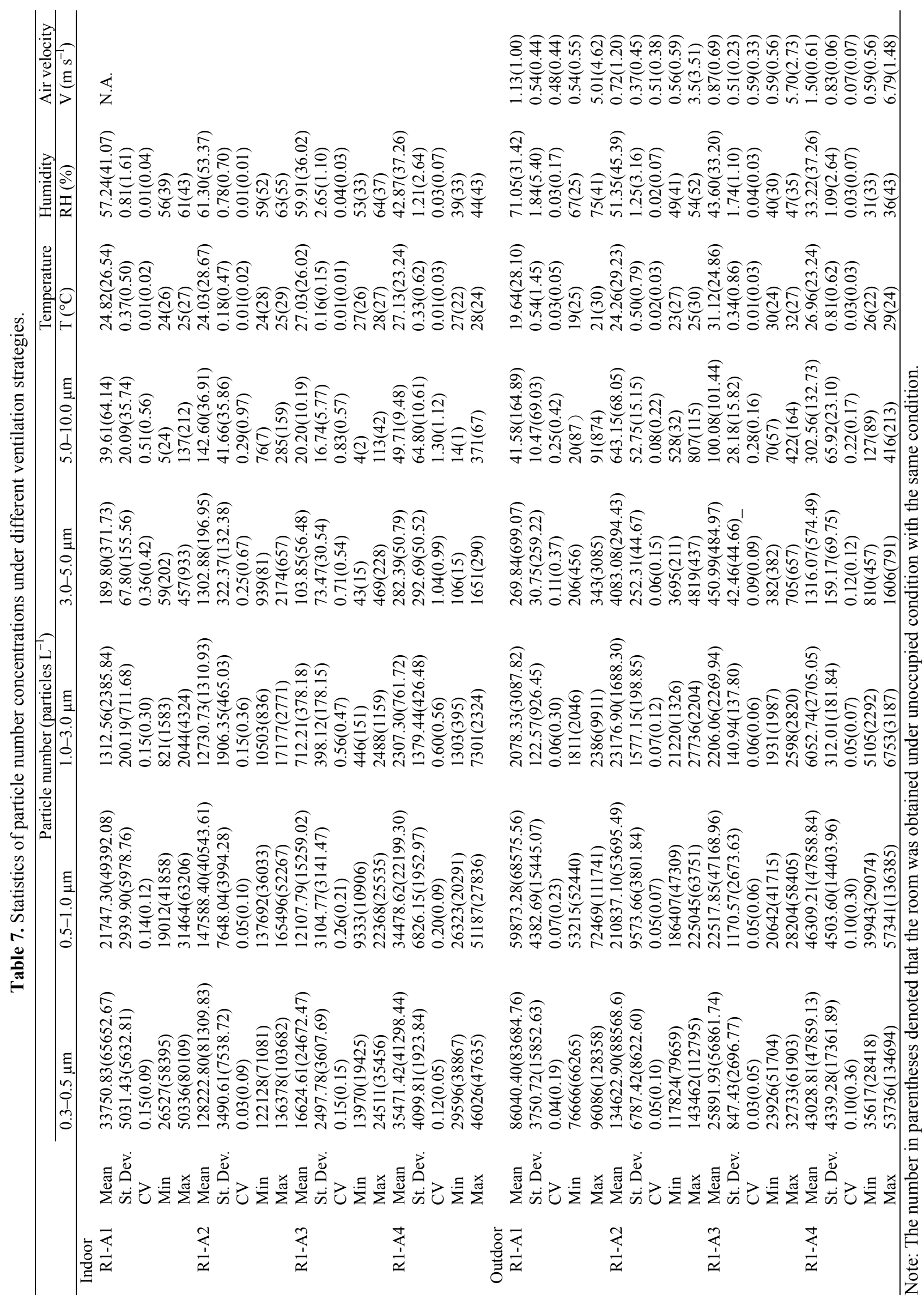




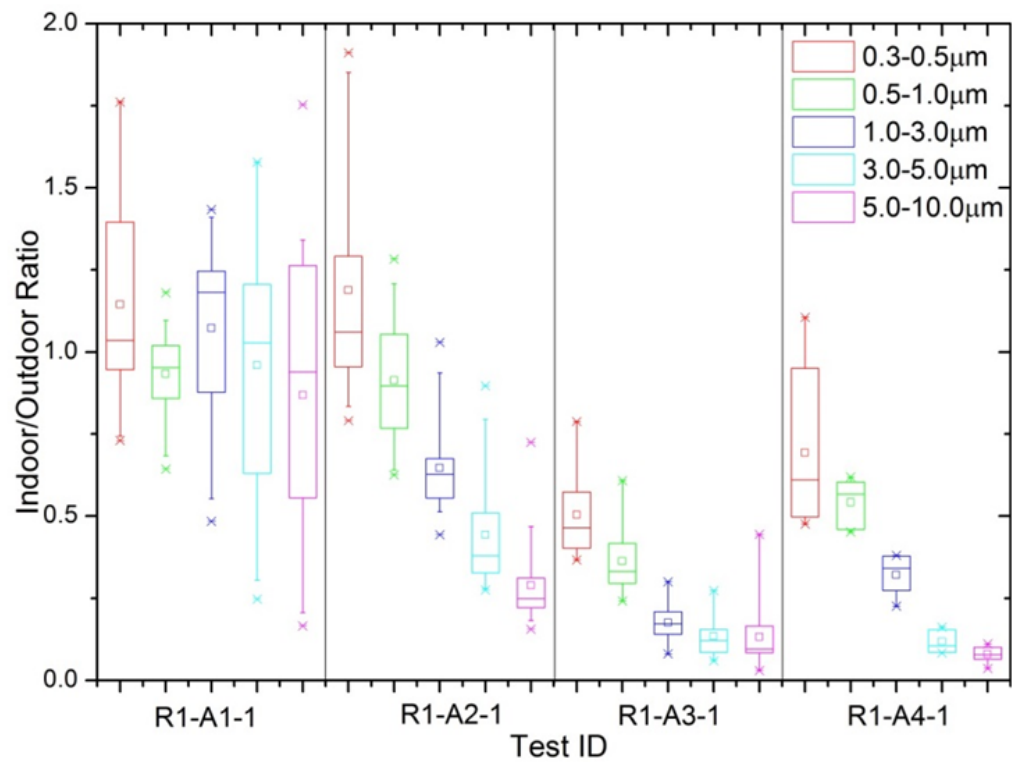

Fig. 15. Effect of particle size on I/O Ratio.

due to the air filter that was applied under R1-A3-1 condition. When I/O ratios in R1-A2-1 and R1-A4-1 were compared, it was found that $\mathrm{I} / \mathrm{O}$ ratios for particles with size $0.3-10 \mu \mathrm{m}$ can be reduced by operation of CCFU. Compared with R1-A4-1 situation, the operation of CCFU with F7 filter in R1-A3-1 situation can be used to efficiently decrease the $\mathrm{I} / \mathrm{O}$ ratios for particles examined in this study, especially those with size $0.3-3.0 \mu \mathrm{m}$.

\section{CONCLUSIONS}

(1) The percentage of plant-related particles in the outdoor air can reach $2-10 \%$ during the transitional season in Nanjing. It is necessary to consider corresponding air filtration measures indoors due to the risk of allergenicity.

(2) During the one continuously monitored day, the outdoor particle concentration reached its maximum in the morning, which means that indoor air filtration should be conducted accordingly.

(3) In the scenario with infiltration, the studied room achieved the air change rate specified in the standard. The penetration factors of particles sized $0.3-0.5 \mu \mathrm{m}$, $0.5-1.0 \mu \mathrm{m}, 1.0-3.0 \mu \mathrm{m}, 3.0-5.0 \mu \mathrm{m}$ and $5.0-10.0 \mu \mathrm{m}$ were $0.78,0.74,0.51,0.38$ and 0.28 , respectively.

(4) The variation in the indoor particle concentration (expressed as the $\mathrm{CV}$ value) was larger when the room was occupied. The I/O ratio decreased as the particle size increased, and the indoor concentration was strongly affected by fluctuations in the outdoor concentration for particles smaller than $1 \mu \mathrm{m}$. By contrast, the indoor concentration of larger particles $(3.0-10 \mu \mathrm{m})$ was more significantly impacted by occupant activity.

\section{ACKNOWLEDGEMENTS}

The authors would like to acknowledge the supports from the National Natural Science Foundation of China
(No. 51508267, 51708286), the Six Talent Peaks Project of Jiangsu Province (JNHB-043), the Natural Science Foundation of Jiangsu Province (No. BK20171015, BK20130946), Postgraduate Research \& Practice Innovation Program of Jiangsu Province in 2018 (KYCX18_1056) and the Scientific Research Foundation from Nanjing Tech University (No. 44214122). Yu Wang would like to appreciate the supported by the National Natural Science Foundation of China (No. 51806096) and Natural Science Foundation of the Jiangsu Higher Education Institutions of China (No. 18KJB560007). Yanjun Li, Xinzhi Lin, Qiansheng Chen, Shoumeng Qiu and Xingchi Jiao are also appreciated for performing experiment. Last but not least, we would like to express our gratitude to anonymous reviewers for their constructive comments.

\section{SUPPLEMENTARY MATERIAL}

Supplementary data associated with this article can be found in the online version at http://www.aaqr.org.

\section{REFERENCES}

Agarwal, N. and Shiva Nagendra, S.M. (2016). Modelling of particulate matters distribution inside the multilevel urban classrooms in tropical climate for exposure assessment. Build. Environ. 102: 73-82.

Bhangar, S., Brooks, Firek, B., Licina, D., Tang, X., Morowitz, M.J., Banfield, J.F. and Nazaroff, W.W. (2016). Pilot study of sources and concentrations of size- resolved airborne particles in a neonatal intensive care unit. Build. Environ. 106: 10-19.

Cao, J., Qin, L., Wu, H. and Chen, L. (2008). Observations on Matured Fruit and Fruit Fairs of Platanus acerifolia. J. Huazhong Agric. Univ. 27: 313-316.

Challoner, A. and Gill, L. (2014). Indoor/outdoor air pollution relationships in ten commercial buildings: 
$\mathrm{PM}_{2.5}$ and $\mathrm{NO}_{2}$. Build. Environ. 80: 159-173.

Chao, C.Y.H., Wan, M.P. and Cheng, E.C.K. (2003). Penetration coefficient and deposition rate as a function of particle size in non-smoking naturally ventilated residences. Atmos. Environ. 37: 4233-4241.

Chatoutsidou, S.E., Ondráček, J., Tesar, O., Tørseth, K., Ždímal, V. and Lazaridis, M. (2015). Indoor/outdoor particulate matter number and mass concentration in modern offices. Build. Environ. 92: 462-474.

Chen, C. and Zhao, B. (2011). Review of relationship between indoor and outdoor particles: I/O ratio, infiltration factor and penetration factor. Atmos. Environ. 45: 275288.

Choi, D.H. and Kang, D.H. (2017). Infiltration of Ambient $\mathrm{PM}_{2.5}$ through Building Envelope in Apartment Housing Units in Korea. Aerosol Air Qual. Res. 17: 598-607.

Cohen, A.J., Brauer, M., Burnett, R., Anderson, H.R., Frostad, J., Estep, K., Balakrishnan, K., Brunekreef, B., Dandona, L., Dandona, R., Feigin, V., Freedman, G., Hubbell, B., Jobling, A., Kan, H., Knibbs, L., Liu, Y., Martin, R., Morawska, L., Pope, C.A., Shin, H., Straif, K., Shaddick, G., Thomas, M., van Dingenen, R., van Donkelaar, A., Vos, T., Murray, C.J.L. and Forouzanfar, M.H. (2017). Estimates and 25-year trends of the global burden of disease attributable to ambient air pollution: an analysis of data from the Global Burden of Diseases Study 2015. Lancet 389: 1907-1918.

Cui, S., Cohen, M., Stabat, P. and Marchio, D. (2015). $\mathrm{CO}_{2}$ tracer gas concentration decay method for measuring air change rate. Build. Environ. 84: 162-169.

Fanger, P.O. (2010). Discomfort caused by odorants and irritants in the air. Indoor Air 8: 81-86.

Feng, L., Zhou, B., Xu, Y., Xue, K., Li, Y., Zhang, R., Wei, P. and Huang, R. (2017). Theoretical investigation and experimental validation on transient variation of particle concentration in a simulated consulting room in hospital. Build. Environ. 117: 1-10.

Gao, Z. and Zhang, J.S. (2015). Modeling particle penetrations through wall assemblies using computational fluid dynamics. Aerosol Sci. Technol. 49: 167-178.

Horemans, B. and Van Grieken, R. (2010). Speciation and diurnal variation of thoracic, fine thoracic and submicrometer airborne particulate matter at naturally ventilated office environments. Atmos. Environ. 44: 1497-1505.

Klepeis, N.E., Nelson, W.C., Ott, W.R., Robinson, J.P., Tsang, A.M., Switzer, P., Behar, J.V., Hern, S.C. and Engelmann, W.H. (2001). The National Human Activity Pattern Survey (NHAPS): A resource for assessing exposure to environmental pollutants. J. Exposure Sci. Environ. Epidemiol. 11: 231-252.

Koponen, I.K., Asmi, A., Keronen, P., Puhto, K. and Kulmala, M. (2001). Indoor air measurement campaign in Helsinki, Finland 1999 - the effect of outdoor air pollution on indoor air. Atmos. Environ. 35: 1465-1477.

Kuo, H.W. and Shen, H.Y. (2010). Indoor and outdoor $\mathrm{PM}_{2.5}$ and $\mathrm{PM}_{10}$ concentrations in the air during a dust storm. Build. Environ. 45: 610-614.

Liddament, M.W. (2000). A review of ventilation and the quality of ventilation air. Indoor Air 10: 193-199.

Long, C.M., Suh, H.H., Catalano, P.J. and Koutrakis, P. (2001). Using time- and size-resolved particulate data to quantify indoor penetration and deposition behavior. Environ. Sci. Technol. 35: 2089-2099.

Lu, Y. (2008). Practical heating and air conditioning design manual. China Architecture \& Building Press, Beijing, China.

Mccreddin, A., Gill, L., Broderick, B. and Mcnabola, A. (2013). Personal exposure to air pollution in office workers in Ireland: Measurement. analysis and implications. Toxics 1: 60-76.

Menzel, A., Matiu, M., Michaelis, R. and Jochner, S. (2017). Indoor birch pollen concentrations differ with ventilation scheme, room location, and meteorological factors. Indoor Air 27: 539-550.

Ministry of Housing and Urban-Rural Development of the People's Republic of China (2012). Design code for heating ventilation and air conditioning of civil buildings. China Architecture \& Building Press, Beijing, China.

Ministry of Housing and Urban-Rural Development of the People's Republic of China (2014). Code for indoor environmental pollution control of civil building engineering, China Planning Press, Beijing, China.

Nathan, R., Katul, G.G., Horn, H.S., Thomas, S.M., Oren, R., Avissar, R., Pacala, S.W. and Levin, S.A. (2002). Mechanisms of long-distance dispersal of seeds by wind. Nature 418: 409-413.

Nazaroff, W.W. (2004). Indoor particle dynamics. Indoor Air 14: 175-183.

Oh, H.J., Nam, I.S., Yun, H., Kim, J., Yang, J. and Sohn, J.R. (2014). Characterization of indoor air quality and efficiency of air purifier in childcare centers, Korea. Build. Environ. 82: 203-214.

Qiao, S. (1986). Studies on the hairs failling of platanus acerifolia II. The hair types and their development. $J$. Nanjing Forest. Univ. 3: 24-30. (In Chinese)

Quang, T.N., He, C., Morawska, L. and Knibbs, L.D. (2013). Influence of ventilation and filtration on indoor particle concentrations in urban office buildings. Atmos. Environ. 79: 41-52.

Rim, D., Gall, E.T., Kim, J.B. and Bae, G.N. (2017). Particulate matter in urban nursery schools: A case study of Seoul, Korea during winter months. Build. Environ. 119: $1-10$.

Ruiz, S.S. and Morales, P.C. (2008). Incidence of the "Platanus" pollen in the atmosphere of Madrid region (Spain). Bot. Complutensis 32: 205-211.

Sc, V.D.Z., Strak, M., Dijkema, M.B., Brunekreef, B. and Janssen, N.A. (2016). The impact of particle filtration on indoor air quality in a classroom near a highway. Indoor Air 27: 291-302.

Shao, Z., Bi, J., Ma, Z. and Wang, J. (2017). Seasonal trends of indoor fine particulate matter and its determinants in urban residences in Nanjing, China. Build. Environ. 125: 319-325.

Stephens, B. and Siegel, J.A. (2012). Penetration of ambient submicron particles into single-family residences 
and associations with building characteristics. Indoor Air 22: 501-513.

Tang, X., You, T., Wu, W., Sun, L. and Li, Z. (2014). Allergenic property and two kinds of common street trees in Nanjing and the control. J. Jishou Univ. 35: 7273.

Thatcher, T.L., Lunden, M.M., Revzan, K.L., Sextro, R.G. and Brown, N.J. (2003). A concentration rebound method for measuring particle penetration and deposition in the indoor environment. Aerosol Sci. Technol. 37: 847-864.

Tran, D.T., Alleman, L.Y., Coddeville, P. and Galloo, J.C. (2014). Indoor-outdoor behavior and sources of sizeresolved airborne particles in French classrooms. Build. Environ. 81: 183-191.

Van Donkelaar, A., Martin, R.V., Brauer, M., Kahn, R., Levy, R., Verduzco, C. and Villeneuve, P.J. (2010). Global estimates of ambient fine particulate matter concentrations from satellite-based aerosol optical depth: Development and application. Environ. Health Perspect. 118: 847855.

Vette, A.F., Rea, A.W., Lawless, P.A., Rodes, C.E., Evans, G., Highsmith, V.R. and Sheldon, L. (2001). Characterization of indoor-outdoor aerosol concentration relationships during the Fresno PM exposure studies. Aerosol Sci. Technol. 34: 118-126.

WHO (2013). Review of evidence on health aspects of air pollution-REVIHAAP Project, World Health Organization, Copenhagen.
Willis, K.J. and Petrokofsky, G. (2017). The natural capital of city trees. Science 356: 374-376.

Wu, Y., Hao, J., Fu, L., Wang, Z. and Tang, U. (2002). Vertical and horizontal profiles of airborne particulate matter near major roads in Macao, China. Atmos. Environ. 36: 4907-4918.

Xie, W. (2013). The research on characterisic of indoor particulate matter and control strategies, $\mathrm{Xi}^{\prime}$ an University of Architecture and Technology, China.

Zang, D. (2012). Landscape dendrology, China Architecture \& Building Press, Beijing, China.

Zhang, J., Liu, Y. and Zhao, L. (2009). The fruit fur characters of Platanus and it's injury function on mice pulmonary. Acta Ecol. Sin. 29: 4380-4385.

Zhao, L., Chen, C., Wang, P., Chen, Z., Cao, S., Wang, Q., Xie, G., Wan, Y., Wang, Y. and Lu, B. (2015). Influence of atmospheric fine particulate matter $\left(\mathrm{PM}_{2.5}\right)$ pollution on indoor environment during winter in Beijing. Build. Environ. 87: 283-291.

Zhu, Y., Hinds, W.C., Krudysz, M., Kuhn, T., Froines, J. and Sioutas, C. (2005). Penetration of freeway ultrafine particles into indoor environments. J. Aerosol Sci. 36: 303-322.

Received for review, March 3, 2018

Revised, August 19, 2018 Accepted, October 1, 2018 